\title{
References
}

1 Gift AG, Narsavage G. Validity of the numeric rating scale as a measure of dyspnea. Am J Crit Care 1998; 7: 200-204.

2 Muza SR, Silverman MT, Gilmore GC, et al. Comparison of scales used to quantitate the sense of effort to breathe in patients with chronic obstructive pulmonary disease. Am Rev Respir Dis 1990; 141: 909-913.

3 Bausewein C, Farquhar M, Booth S, et al. Measurement of breathlessness in advanced disease: a systematic review. Respir Med 2007; 101: 399-410.

4 Gift AG. Validation of a vertical visual analogue scale as a measure of clinical dyspnea. Rehabil Nurs 1989; 14: $323-325$.

5 Wilcock A, Crosby V, Clarke D, et al. Repeatability of breathlessness measurements in cancer patients. Thorax 1999; 54: 375

6 Molassiotis A, Charalambous A, Taylor $\mathrm{P}$, et al. The effect of resistance inspiratory muscle training in the management of breathlessness in patients with thoracic malignancies: a feasibility randomised trial. Support Care Cancer 2015; 23: 1637-1645.

7 Simon ST, Higginson IJ, Benalia H, et al. Episodic and continuous breathlessness: a new categorization of breathlessness. J Pain Symptom Manage 2013; 45: 1019-1029.

8 Herigstad M, Hayen A, Evans E, et al. Dyspnea-related cues engage the prefrontal cortex: evidence from functional brain imaging in COPD. Chest 2015; 148: 953-961.

9 Oxberry SG, Torgerson DJ, Bland JM, et al. Short-term opioids for breathlessness in stable chronic heart failure: a randomized controlled trial. Eur J Heart Fail 2011; 13: 1006-1012.

10 Bausewein C, Booth S, Gysels M, et al. Understanding breathlessness: cross-sectional comparison of symptom burden and palliative care needs in chronic obstructive pulmonary disease and cancer. J Palliat Med 2010; 13: 1109-1118.

11 Farquhar MC, Prevost A, McCrone P, et al. Is a specialist breathlessness service more effective and cost-effective for patients with advanced cancer and their carers than standard care? Findings of a mixed-method randomised controlled trial. BMC Med 2014; 12: 194.

12 Farquhar MC, Higginson IJ, Fagan P, et al. The feasibility of a single-blinded fast-track pragmatic randomised controlled trial of a complex intervention for breathlessness in advanced disease. BMC Palliat Care 2009; 8: 9.

13 Yorke J, Moosavi SH, Shuldham C, et al. Quantification of dyspnoea using descriptors: development and initial testing of the Dyspnoea-12. Thorax 2010; 65: 21-26.

14 Adams L, Lane R, Shea SA, et al. Breathlessness during different forms of ventilatory stimulation: a study of mechanisms in normal subjects and respiratory patients. Clin Sci (Lond) 1985; 69: 663-672.

\section{Asthmatics with high levels of serum surfactant protein D have more severe disease}

\author{
To the Editor:
}

Pulmonary surfactant is a mixture of lipids and surfactant-specific proteins that covers the alveolar surface, as well as the terminal conducting airways, lowering the surface tension at the air-liquid interface during breathing. The involvement of pulmonary surfactant in the pathophysiology of asthma has been suggested [1-4]. An interesting working hypothesis is that the surface tension of the peripheral airways is altered in asthma, because the inflammatory process affects the structure and function of surfactant, leading to excessive airway narrowing and features of air trapping. We explored whether serum levels of surfactant protein D (SP-D) in asthmatics are related to the severity of the disease. In addition, we aimed to assess whether serum SP-D correlated with functional abnormalities of peripheral airways.

A total of 44 unselected consecutive asthmatics with different disease severity according to the Global Initiative for Asthma (GINA) guidelines [5] were recruited at the Outpatient Allergy and Asthma Clinic of DiBiMIS, University of Palermo, Italy. All subjects were skin test positive to at least one aeroallergen, and none was a current or former smoker. Mild asthmatics (six males, 13 females; mean \pm SD age $38.1 \pm 12.4$ years) were on rescue medication (step 1 treatment); moderate asthmatics (nine males, three females; mean \pm SD age $47 \pm 12.7$ years) were on beta- 2 adrenergic long-acting bronchodilators (LABA) and inhaled corticosteroids (ICS) at low or medium doses (step 2-4 treatment); and severe asthmatics (six males, seven females; mean \pm SD age $54.7 \pm 12.3$ years) were under treatment with LABA/ICS at high doses as well as anti-IgE treatment (step 5 treatment). All inhaled medications were withdrawn $48 \mathrm{~h}$ prior to the study day, and salbutamol was the only drug allowed. Nine healthy subjects (four males, five females; 
mean \pm SD age $44.0 \pm 12.5$ years) served as controls. None of them was ever exposed to respiratory medications. The local ethics committee in Palermo, Italy approved the protocol (IRB registration number: 124/2012), and written informed consent was obtained from each participant.

The study was conducted over 2 days. During the first visit, each subject underwent clinical assessment using the asthma control test (ACT) to establish the severity of the disease based on the level of treatment required to control their respiratory symptoms. Functional assessment included measures of dynamic and static lung volumes using a body box (Viasys Respiratory Care; Vmax Sensormedics, Yorba Linda, CA, USA) [6]. To perform the SP-D analysis, $\sim 3 \mathrm{~mL}$ venous blood was drawn in the morning from fasted patients. SP-D concentration in serum samples was measured using a commercially available EIA/ELISA kit (Quantikine ELISA; R\&D System, Minneapolis, MN, USA). On a separate occasion, peripheral airway resistance was measured with an impulse oscillometry system (IOS) using the Jaeger MasterScreen-IOS (Carefusion Technologies, San Diego, CA, USA). Normally distributed data are reported as mean \pm SD and skewed data as median (range). Comparisons between groups were performed by ANOVA or Mann-Whitney U test, as appropriate.

The serum SP-D values were $3.1 \pm 1.7 \mathrm{ng} \cdot \mathrm{mL}^{-1}$ in the healthy controls, and $7.9 \pm 4.6 \mathrm{ng} \cdot \mathrm{mL}^{-1}, 15.1 \pm 10.6 \mathrm{ng} \cdot \mathrm{mL}^{-1}$ and $17.0 \pm 12.5 \mathrm{ng} \cdot \mathrm{mL}^{-1}$ in the mild, moderate and severe asthmatics, respectively $(\mathrm{p}=0.001)$. Serum SP-D was significantly higher in moderate and severe asthmatics compared with healthy controls $(p<0.001$ and $p=0.017$, respectively) and compared with mild asthmatics ( $\mathrm{p}=0.008$ and $\mathrm{p}=0.016$, respectively). Serum SP-D was not statistically different between mild asthmatics and healthy subjects, and between moderate and severe asthmatics (figure 1). In the whole group, serum SP-D was shown to inversely correlate with forced expiratory volume in $1 \mathrm{~s}(\mathrm{FEV} 1) \%$ predicted $\left(\mathrm{r}_{\mathrm{s}}=-0.49 ; \mathrm{p}=0.0002\right)$, forced vital capacity $(\mathrm{FVC}) \%$ pred $\left(\mathrm{r}_{\mathrm{s}}=-0.88\right.$; $\mathrm{p}<0.041)$ and $\mathrm{FEV} 1 / \mathrm{FVC} \%$ pred $\left(\mathrm{r}_{\mathrm{s}}=-0.48 ; \mathrm{p}=0.0003\right)$. Importantly, the SP-D serum concentrations were $7.9 \pm 4.6 \mathrm{ng} \cdot \mathrm{mL}^{-1}$ in the controlled asthmatics, $14.6 \pm 9.9 \mathrm{ng} \cdot \mathrm{mL}^{-1}$ in the partially controlled asthmatics and $17.3 \pm 12.8 \mathrm{ng} \cdot \mathrm{nL}^{-1}$ in the uncontrolled asthmatics $(\mathrm{p}=0.017)$. Serum SP-D did not correlate with the age of the study subjects or duration of the disease $(\mathrm{p}>0.05)$.

Serum SP-D was shown to inversely correlate with forced expiratory flow at $25-75 \%$ of FVC $\%$ pred $\left(r_{s}=-0.25\right.$; $\mathrm{p}=0.0003)$, forced expiratory flow at $25 \%$ of $\mathrm{FVC} \%$ pred $\left(\mathrm{r}_{\mathrm{s}}=-0.44 ; \mathrm{p}=0.0001\right)$, forced expiratory flow at $50 \%$ of FVC $\%$ pred $\left(\mathrm{r}_{\mathrm{s}}=-0.52 ; \mathrm{p}=0.0001\right)$ and forced expiratory flow at $75 \%$ of FVC $\%$ pred $\left(\mathrm{r}_{\mathrm{s}}=-0.46 ; \mathrm{p}=0.0006\right)$. In addition, serum SP-D was positively correlated with respiratory resistance at $5-20 \mathrm{~Hz}(R 5-20)\left(\mathrm{r}_{\mathrm{s}}=0.41 ; \mathrm{p}<0.0001\right)$ and residual volume $\%$ pred $\left(r_{s}=0.26 ; p=0.04\right)$. No significant relationship was found between serum SP-D and total lung capacity $\%$ pred $\left(\mathrm{r}_{\mathrm{s}}=0.42 ; \mathrm{p}=0.77\right)$. A multiple regression model including all functional indices showed that $R 5-20$ was the single best predictor of SP-D ( $\mathrm{p}=0009$ ).

The current study was designed to test the hypothesis that serum levels of SP-D are associated with the severity of asthma. Our primary finding was that serum SP-D was significantly higher in asthmatics with persistent symptoms compared with healthy controls, and increased with the magnitude of airway obstruction and the loss of asthma control. In addition, we found that higher serum concentrations of SP-D were associated with small airways dysfunction. These findings suggest that inflammatory-induced abnormalities of the periphery of the lung (small airways and alveoli) may affect surfactant integrity, and imply that serum concentrations of SP-D may serve as a biomarker of asthma severity.

FIGURE 1 Differences between groups for serum surfactant protein D (SP-D). Comparisons between groups were performed using the Mann-Whitney $U$ test, with follow-up analysis for multiple comparison (pairwise with adjusted p-values).

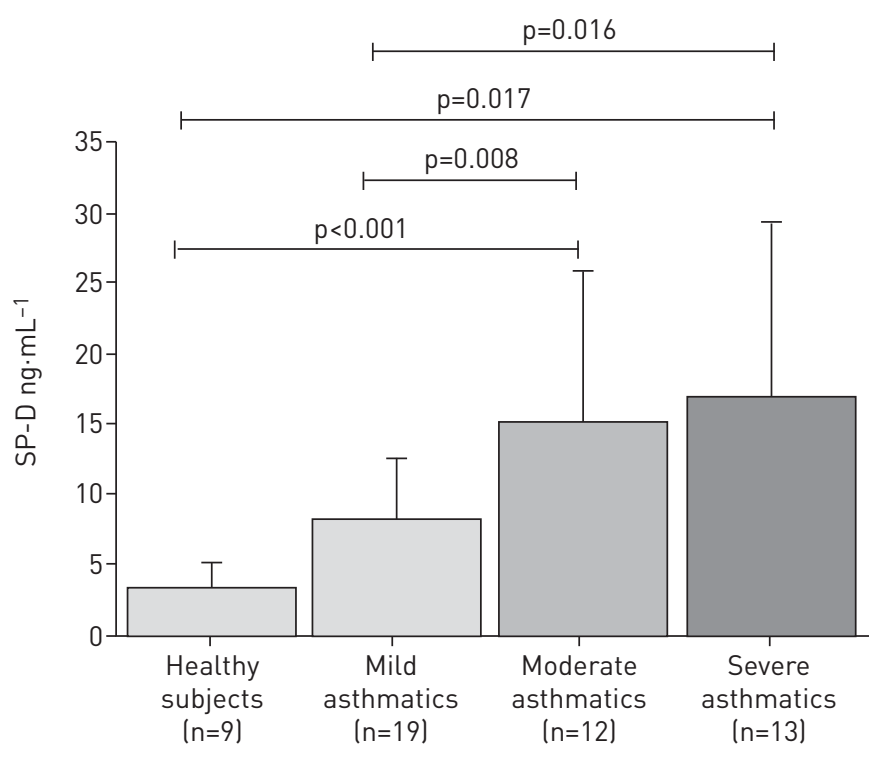


Surfactant prevents alveolar collapse and reduces surface tension at the air-liquid interface. Importantly, surfactant is also the main determinant in maintaining the patency of the peripheral airways, because it stabilises the airways and prevents their collapse. In the current study, we demonstrated an increase in serum SP-D with increasing severity of asthma. It is plausible to hypothesise that the inflammatory-mediated increase in macromolecular permeability of the bronchial microvasculature allows spillover from the lung to the blood of large macromolecules, such as the hydrophilic surfactant proteins [7,8]. Alternatively, the increased levels of SP-D in serum could be also explained by an increased local synthesis of surfactant proteins by undifferentiated epithelial cells induced by local inflammation [9]. Indeed, neutrophils and eosinophils have been shown to influence surfactant homeostasis [10]. Koopmans et al. [3] recently demonstrated that serum SP-D concentrations were significantly higher in 50 allergic subjects, and further increased after allergen challenge. In addition to these findings, we demonstrated that serum SP-D increased when asthma becomes persistent.

The findings of the current study provide a potential explanation for the pathophysiological mechanisms of asthma. The number of recruited subjects is relatively small since the study was intended as explorative, and therefore, conclusions should be drawn with caution. Indeed, SP-D promotes the clearance of pathogens, enhances the phagocytosis of apoptotic cells and inhibits pro-inflammatory cytokine release by effector cells [11-13]. We favour the hypothesis that altered surfactant would be the underlying cause of the impairment in the bronchodilatory effect of deep inspirations that has been observed in asthma [14]. This is because the effectiveness of the beneficial effects of lung inflations on airways is dependent on the interdependence between the parenchyma and the airway walls. Any factor unlinking the airways and the parenchyma, such as increased surface tension, could cause a reduction in the distending forces that are applied on the airways. Pyrgos et al. [15] showed that the ability of lung inflation to distend obstructed airways decreased with the severity of asthma, and the impairment in the dilatory ability of deep inspirations was more evident in the most peripheral airways, upon which the distending forces are, for the greater part, expected to act and where surfactant alterations would play a major role. Our findings clearly showed that serum levels of SP-D were strongly associated with functional parameters of small airway abnormalities.

In summary, we demonstrated that concentrations of SP-D are increased in asthmatics, when the disease becomes persistent. Moreover, serum concentrations of SP-D were associated with the degree of small airways dysfunction. Surfactant dysfunction adds to our understanding of the pathophysiological scenario of airway obstruction in asthma, probably by opposing the dilatory ability of lung inflation on narrowed airways, thus influencing the severity of asthma. asthma http://ow.ly/YdeG9

Alida Benfante, Salvatore Battaglia, Stefania Principe, Chiara Di Mitri, Alessandra Paternò, Mario Spatafora and Nicola Scichilone

Dipartimento di Biomedicina e Medicina Specialistica, Sezione di Pneumologia, University of Palermo, Palermo, Italy.

Correspondence: Nicola Scichilone, Dipartimento di Biomedicina e Medicina Specialistica, Sezione di Pneumologia, University of Palermo, via Trabucco 180, 90146 Palermo, Italy. E-mail: nicola.scichilone@unipa.it

Received: Nov 112015 | Accepted after revision: Jan 302016 | First published online: March 172016

Conflict of interest: None declared.

\section{References}

Hohlfeld JM. The role of surfactant in asthma. Respir Res 2002; 3: 4.

2 Iwamoto H, Gao J, Koskela J, et al. Differences in plasma and sputum biomarkers between COPD and COPDasthma overlap. Eur Respir J 2014; 43: 421-429.

3 Koopmans JG, van der Zee JS, Krop EJ, et al. Serum surfactant protein D is elevated in allergic patients. Clin Exp Allergy 2004; 34: 1827-1833.

4 Pastva AM, Wright JR, Williams KL. Immunomodulatory roles of surfactant proteins A and D: implications in lung disease. Proc Am Thorac Soc 2007; 4: 252-257.

5 Global Initiative for Asthma (GINA). Global Strategy for Asthma Management and Prevention. www.ginasthma.org Date last updated: April 2015.

6 Miller MR, Hankinson J, Brusasco V, et al. Standardisation of spirometry. Eur Respir J 2005; 26: 319-338.

7 Holtzman MJ. Asthma as a chronic disease of the innate and adaptive immune systems responding to viruses and allergens. J Clin Invest 2012; 122: 2741-2748.

8 Hastings RH, Grady M, Sakuma T, et al. Clearance of different-sized proteins from the alveolar space in humans and rabbits. J Appl Physiol 1992; 73: 1310-1316.

$9 \mathrm{Xu}$ J, Singhera GK, Dorsheid DR. Expression of surfactant protein D in airways of asthmatics and interleukin-13 modulation of surfactant protein D in human models of airway epithelium. Respir Res 2015; 16: 26.

10 Jain-Vora S, Wert SE, Temann UA, et al. Interleukin-4 alters epithelial cell differentiation and surfactant homeostasis in the postnatal mouse lung. Am J Respir Cell Mol Biol 1997; 17: 541-551. 
11 Schaub B, Westlake RM, He $\mathrm{H}$, et al. Surfactant protein D deficiency influences allergic immune responses. Clin Exp Allergy 2004; 34: 1819-1826.

12 Ledford JG, Addison KJ, Foster MW, et al. Eosinophil-associated lung diseases. A cry for surfactant proteins A and D help? Am J Respir Cell Mol Biol 2014; 51: 604-614.

13 Ofek I, Mesika A, Kalina M, et al. Surfactant protein D enhances phagocytosis and killing of unencapsulated phase variants of Klebsiella pneumoniae. Infect Immun 2001; 69: 24-33.

14 Scichilone N, Marchese R, Soresi S, et al. Deep inspiration-induced changes in lung volume decrease with severity of asthma. Respir Med 2007; 101: 951-956.

15 Pyrgos G, Scichilone N, Togias A, et al. Bronchodilation response to deep inspirations in asthma is dependent on airway distensibility and air trapping. J Appl Physiol 2011; 110: 472-479.

\title{
Incorporating therapeutic drug monitoring into the World Health Organization hierarchy of tuberculosis diagnostics
}

\author{
To the Editor:
}

Tuberculosis (TB), once considered as a disease of the past generally afflicting poor people, still claims 1.5 million lives annually [1]. Although $86 \%$ of patients with drug susceptible TB are cured with established first-line drugs, treatment is often longer than 6 months due to slow response, compliance problems or adverse drug reactions. In addition, emergence of drug-resistant Mycobacterium tuberculosis strains with an unacceptably low treatment success rate of $50 \%$ and TB-HIV co-infection have challenged the goals of global TB control and elimination [1].

Pharmacokinetic variability is a major driver of acquired drug resistance due to comorbidities, co-medications and intra-individual differences [2]. Therefore, monitoring the exposure-response relationship by incorporating pharmacokinetics and minimum inhibitory concentration (MIC) of the anti-TB drugs would conceivably help combat the current challenges of drug resistance, toxicity, relapse and nonresponse [3]. Drug exposure over time (area under the concentration-time curve $\left(\mathrm{AUC}_{0-24}\right)$ ) and peak serum concentration $\left(\mathrm{C}_{\max }\right)$ are the two parameters that, in combination with MIC, predict development of acquired drug resistance and are expressed as a ratio of $\mathrm{AUC}_{0-24} / \mathrm{MIC}$ or $\mathrm{C}_{\max } / \mathrm{MIC}$ [4]. For instance, a patient with serum concentrations below the suggested therapeutic threshold may still achieve a successful treatment outcome because of a low MIC of the offending organism [5]. However, patients with altered pharmacokinetic parameters (e.g. because of comorbidities), abnormally low body mass index, low $\mathrm{AUC}_{0-24}$ and high MIC values are at the peril of treatment failure [6].

For the measurement of drug concentrations in areas with limited resources, dried blood spot (DBS) sampling can be introduced as an easy sampling procedure. In DBS sampling, whole blood is obtained via finger prick and dropped onto a sampling paper which is dried, extracted and then analysed by validated methods such as liquid chromatography-tandem mass spectrometry (LC-MS/MS). DBS sampling overcomes the costs and logistic problems related to venous blood sampling such as larger sample volume, invasion with needles, storage conditions, transportation and biohazard risks. Finally, this technology is highly appropriate for children affected with TB. Obtaining a full time concentration profile for $\mathrm{AUC}_{0-24} /$ MIC ratio is not feasible in the rural clinics. Therefore, limited sampling strategies could be applied to estimate the total exposure [7].

To optimise drug therapy, therapeutic drug monitoring (TDM) has become a standard clinical technique, as agreed among researchers and healthcare policy makers [8]. Despite broad acceptance, TDM has not yet been implemented in resource constrained countries with a high TB burden [9]. This might be due to the limited budget the health sector receives and the lack of advanced bioanalytical infrastructure for performing TDM. To overcome this problem we propose to organise the logistics for TDM in a similar way as for TB diagnostics. Here we describe the tools and strategy for implementing TDM at three levels (figure 1). 